Original research

\title{
Comparative study of nomophobia among Spanish and Portuguese nursing students
}

\author{
Lorena Gutiérrez-Puertas ${ }^{a}$, Verónica V. Márquez-Hernández ${ }^{b, *}$, Leonel São-Romão-Preto ${ }^{c}$, \\ Genoveva Granados-Gámez ${ }^{\mathrm{b}}$, Vanesa Gutiérrez-Puertas ${ }^{\mathrm{a}}$, Gabriel Aguilera-Manrique ${ }^{\mathrm{b}}$ \\ ${ }^{a}$ Department of Nursing, Physiotherapy and Medicine, Faculty of Health Sciences, University of Almeria, Sacramento S/N, en La Cañada de San Urbano, CP: 04120, Spain \\ ${ }^{\mathrm{b}}$ Department of Nursing, Physiotherapy and Medicine, Research Group for Health Sciences CTS-451, Faculty of Health Sciences, University of Almeria, Sacramento S/N, en \\ La Cañada de San Urbano, CP: 04120, Spain \\ ${ }^{\mathrm{c}}$ School of Health, Polytechnic Institute of Bragança, 5300-253, Bragança, Portugal
}

\section{A R T I C L E I N F O}

\section{Keywords:}

Nomophobia

Nursing students

Smartphone

Comparative study

\begin{abstract}
A B S T R A C T
Nomophobia is the fear of leaving the house without a mobile and being out of mobile phone contact and affects different areas of a person's life, especially in terms of social, work and academic relationships due to a dependence on the use of smartphones. Discovering the prevalence of nomophobia among nursing students is very important, as the misuse of smartphones in clinical practice may cause distractions, affecting the quality of care and putting patient safety at risk. Furthermore, it can lead to poorer academic performance during class. The aim of this study was to compare the levels of nomophobia experienced by nursing students at the University of Almeria, Spain and the Polytechnic Institute of Braganza, Portugal. A comparative descriptive observational study was carried out. A nomophobia questionnaire adapted to the Spanish and Portuguese sociolinguistic context was employed; 258 participants comprised the subjects of study. The main results showed both Spanish and Portuguese nursing students scored higher than average regarding levels of nomophobia. However, the scores gathered from items on the questionnaire were generally higher among the Portuguese population than the Spanish one. The Portuguese students (54.7\%) felt more anxious than the Spanish students (35.4\%) if their battery ran out. Similarly, the Portuguese population showed a greater need for instant communication with their family and friends. In conclusion, the dimensions explored indicate significant levels of nomophobia among both nursing student populations, with higher levels among the Portuguese population than the Spanish.
\end{abstract}

\section{Introduction}

Information and Communication Technologies (ICTs) have become an essential part of our lives (Lee et al., 2014). Many people, particularly the younger generations, use new technologies for studying, playing, keeping in contact with friends and many other activities (Cho and Lee, 2016). ICTs can change our way of forming relationships and socializing with those around us, with both positive and negative effects; it all depends on how we use - or abuse - them (Gokcersanlan et al., 2016).

According to data from the National Statistics Institute (INE) from 2014 , in Spain it was found that $97.1 \%$ of young people had a mobile phone. Several studies have shown high levels of smartphone dependency among university students (Bae, 2017; Mei et al., 2018) with higher levels among girls than boys (Bae, 2017; González et al., 2015;
Leung, 2017; Mei et al., 2018). Spanish adolescents use the internet via mobile telephones in 90.4\% (INE, 2014). In Portugal, the National Statistics Institute (2014) estimated that $89 \%$ of the Portuguese population has a mobile telephone. Portuguese adolescents use the internet via mobile telephones in 77\% (Pontes and Patrão, 2014).

Currently, we can see that in day-to-day life, whether in private or in public, a significant number of children, adolescents, young people and adults display behaviors which can be defined as addictive (Kuss and Griffiths, 2017). For example, they spend a lot of time on videogames and social networks such as Facebook and in general on mobile phone use and new technologies, related tools and their applications (Beyens et al., 2016). Kuss and Griffiths (2017) has stated that nomophobia may be part of online social networking sites addiction. Furthermore, in the work environment, more and more people are dedicating time to this type of activities, neglecting their work-related

\footnotetext{
* Corresponding author.

E-mail addresses: lgp524@ual.es (L. Gutiérrez-Puertas), vmh380@ual.es (V.V. Márquez-Hernández), leonelpreto@ipb.pt (L. São-Romão-Preto), genoveva@ual.es (G. Granados-Gámez),vgp919@ual.es (V. Gutiérrez-Puertas), gaguiler@ual.es (G. Aguilera-Manrique).
} 
duties and relationships with their coworkers, leading to loss of employment and high employee turnover (Cho and Lee, 2016).

Problematic smartphone use has alarmingly increased in developed countries in the last years. The problematic use of smartphones can affect social relationships, decreasing their quality (Vanden Abeele et al., 2016). Habuchi (2005) has stated that mobile telephones can negatively affect the quality of interpersonal relationships, furthermore, use of smartphones has also been found to produce a disconnection from one's surroundings. Billieux et al. (2014) proposed classifying the use of mobile telephones as an abusive use rather than an addiction. There is no unanimous consensus regarding its definition, with different authors suggesting terms such as addiction, abusive use, problematic use and excessive use (Bianchi and Phillips, 2005).

In light of the aforementioned, the term nomophobia has emerged. The term nomophobia is normally used to refer to a dependence of users on their smartphones or an addiction to intelligent mobile telephones (Dixit et al., 2010). Nomophobia is described as "the fear of being out of mobile phone contact or an uncontrollable fear of leaving your house without a mobile phone" (SecurEnvoy, 2012). The term nomophobia is an abbreviation of the expression "no-mobile-phone phobia" (Yildirim and Correia, 2015).

Various studies have revealed the presence of nomophobia in the population. A study stated that $75 \%$ of Indian medical students showed nomophobic behaviors and $83 \%$ had experienced a panic attack when they were not able to use their smartphone (Sharma et al., 2015). In another study, with a sample of 18-24 year olds, $66 \%$ displayed nomophobic behaviors (SecurEnvoy, 2012). A further study with Turkish university students indicated that $42.6 \%$ of the sample had nomophobia (Yildirim et al., 2016). In Portugal, although internet dependence among adolescents is a significant concern, there have been few studies related to the topic (Pontes et al., 2016). The National Plan for Addictive and Dependent Behaviors 2013-2020, approved by the Council of Ministers (Portugal), considers extending measures to addictive or dependent behaviors related to gambling or the internet.

Regarding nursing professionals, 75\% admit to having used their mobile telephone at work for personal matters (McBride et al., 2015). Interruptions caused by the inappropriate use of such devices may lead to essential tasks such as healthcare being overlooked (Gill et al., 2012), relevant patient information being lost or missed, attention deficit and poorer professional-patient communication (Alsos et al., 2012).

Ultimately, nomophobia affects different areas of a person's life, especially in terms of social, work and academic relationships due to a dependence on the use of smartphones (Argumosa-Villar et al., 2017). More specifically, some authors have found that nursing students get distracted in clinical practice due to the use of smartphones (AguileraManrique et al., 2018; Cho and Lee, 2016). It is therefore important to determine the degree of nomophobia among a population which is immersed in the digital age; such is the case of students. Hence, the main aim of the study was to compare the levels of nomophobia among nursing degree students from the University of Almeria, Spain and the Polytechnic Institute of Braganza, Portugal.

\section{Method}

\subsection{Study design}

A comparative study of the levels of nomophobia among Spanish and Portuguese nursing degree students was carried out.

\subsection{Participants}

The subjects of this study were 258 participants, 130 of which were from Spain and 128 of which were from Portugal. The study was carried out at the University of Almeria (Spain) and the Polytechnic Institute of Braganza (Portugal). These two universities were selected due to a joint project based on new technologies that researchers at these universities are working on. The participants had to comply with the following inclusion criteria: 1) To be enrolled on a nursing degree at the University of Almeria in the case of Spanish students or at the Polytechnic Institute of Braganza for Portuguese students, 2) To give consent to participate in the study. 3) To not be on clinical placement. Before enrolling at university, the students came from different educational backgrounds: high school, vocational training etc. Sample selection was carried out through convenience sampling, which is why students on clinical placements were not considered, as they were not attending classes at university. Therefore some years, such as 4th year in both countries, were not considered. Data collection took place during the $2017 / 2018$ academic year.

\subsection{Measures}

The Nomophobia Questionnaire (NMP-Q) was developed and validated by Yildirim and Correia (2015). The questionnaire includes 20 items valued on a Likert-type scale of $1-7$, with 1 corresponding to "strongly disagree" and 7 "strongly agree". The total score is calculated by adding up the values of each item, leading to a score of between 20 and 140 points. Higher scores reflect a more severe degree of nomophobia. Exploratory factor analysis revealed a four-factor structure for the NMP-Q, corresponding to the dimensions of nomophobia: not being able to access information (items 1-4) (range from 4 to 28 points); giving up convenience (items 5-9) (range from 5 to 35 points); not being able to communicate (items 10-15) (range from 6 to 42) and losing connectedness (items 16-20) (range from 5 to 35). The score for each factor was calculated by adding the items which it included. Reliability, which verifies the scale's internal consistency, was a Cronbach's alpha value of 0.945 . The NMP-Q was shown to produce valid and reliable scores.

The NMP-Q questionnaire was adapted and validated for the Spanish sociolinguistic context, with a Cronbach's alpha value of .927, by Gutiérrez-Puertas et al. (2016), and used with the sample of Spanish students. The NMP-Q was also used with the Portuguese students, adapted to the Portuguese sociolinguistic context. Only two factors were obtained in the questionnaire's adaption and validation process, with a total explained variance of $62.98 \%$. These factors were: "not having access to information and connectivity" and "not being able to communicate". The factor "not having access to information and connectivity" consisted of 14 items (1-9, 16-20) (range from 14 to 98 points), and the factor "not being able to communicate" of 6 items (10-15) (range from 6 to 42 points). The internal consistency of the total scale achieved very good results, with a Cronbach's $\alpha$ value of 0.953. The result of the Kaiser-Meyer-Olkin (KMO) test was 0.941, the same as the result obtained in the original version.

\subsection{Data collection}

For data collection, students enrolled on the nursing degree at the University of Almeria (Spain) or the Polytechnic Institute of Braganza (Portugal) were invited to participate. Once their collaboration had been requested, the main researcher provided (in person) those students interested in participating with the Spanish or Portuguese version of the Nomophobia questionnaire respectively. Prior to students completing the information, the researcher explained the aim of the study together with the voluntary nature of their participation. The questionnaires were completed in a university classroom in 30-40\& $\# \mathrm{x} 202 \mathrm{~F} ; \mathrm{min}$. Once finished, the researcher thanked the participants for their collaboration. The study began January to June 2016.

\subsection{Ethical considerations}

Regarding the ethical aspects of the study, the research project was approved by the Department of Nursing, Physiotherapy and Medicine Research Committee at the University of Almeria. The ethics approval 
number is $08 / 2016$. The committee is composed of expert professors belonging to different areas (nursing, medicine, physiotherapy). This Research Committee reports and controls compliance with deontological norms for scientific research, in accordance with the Declaration of Helsinki, the legislation of the European Community, the Spanish State and the Decrees of control and monitoring competence of the Autonomous Community. All of the participants in the study received information regarding its aim, anonymity of data, the voluntary nature of their participation, and the option to withdraw from the study at any time. All participants were of legal age. Students who agreed to take part signed the informed consent form which gave detailed information about the study.

\subsection{Data analysis}

The data was analyzed using the statistics program SPSS v.22. For quantitative variables, central tendency and dispersion measures were employed, while for qualitative variables, the data was tabulated and the relative frequencies and percentages were calculated. In order to make comparisons between groups, a contrast test for quantitative variables with parametric distribution using Student's t-test was carried out (having previously checked the normal distribution with the Kolmogorov-Smirnov test). To compare categorical variables, the chisquare test was employed. For non-parametric distributions, the $\mathrm{U}$ Mann Whitney test was used and for the correlation of quantitative variables, the Spearman test was utilized. A p\&\#x202F; < \& \#x202F;0.05 was considered as significant.

\section{Results}

\subsection{Sample characteristics}

The sample consisted of a total of 258 participants, 128 of which were from Portugal and 130 from Spain. Of the total, 19\% (n\& $\# \times 202 \mathrm{~F} ;=\& \# \times 202 \mathrm{~F} ; 49) \quad$ were male and $81 \% \quad(\mathrm{n} \& \# \mathrm{x} 202 \mathrm{~F} ;=\&$ $\# x 202 F ; 209$ ) were female. The average age was 20.78 (SD\&\#x202F; = $\& \# \times 202 F ; 3.16)$, with a minimum age of 17 and a maximum age of 39 (Table 1).

\subsection{Nomophobia questionnaire by dimension}

Four dimensions were defined for the Spanish population: (1) not being able to communicate, (2) losing connectedness, (3) not being able to access information and (4) giving up convenience. The average score for the dimension "not being able to communicate" was 25.44 (SD\& $\# \mathrm{x} 202 \mathrm{~F} ;=\& \# \mathrm{x} 202 \mathrm{~F} ; 0.90$ ) (range from 6 to 42 points). In relation to gender, the average score for males for this factor was 25.39 (SD\& $\# \mathrm{x} 202 \mathrm{~F} ;=\& \# \mathrm{x} 202 \mathrm{~F} ; 6.65)$, while for women, the average was 24.49

Table 1

Sociodemographic characteristics of the sample.

\begin{tabular}{|c|c|c|c|c|c|}
\hline \multirow[t]{2}{*}{ Variable } & \multicolumn{2}{|l|}{ Spain } & \multicolumn{2}{|c|}{ Portugal } & \multirow[t]{2}{*}{$\mathrm{p}$} \\
\hline & $\mathrm{n}$ & $\%$ & $\mathrm{n}$ & $\%$ & \\
\hline \multicolumn{6}{|l|}{ Sex } \\
\hline Men & 33 & 25.4 & 16 & 12.5 & $0.008^{\mathrm{a}}$ \\
\hline Women & 97 & 74.6 & 112 & 87.5 & \\
\hline \multicolumn{6}{|l|}{ Grade } \\
\hline First & - & - & 56 & 43.8 & $<0.05^{\mathrm{a}}$ \\
\hline Second & 71 & 54.6 & 26 & 20.3 & \\
\hline Third & 59 & 45.4 & 46 & 35.9 & \\
\hline Years & $21.52^{c}$ & $3.57^{d}$ & $20.04^{c}$ & $2.48^{\mathrm{d}}$ & $0.195^{\mathrm{b}}$ \\
\hline
\end{tabular}

\footnotetext{
a Chi squared.

b U Mann-Whitney.

c Mean.
}

d Standard Deviation.
(SD\&\#x202F; = \&\#x202F;5.65).

With regard to "losing connectedness", the average score was 16.79 (SD\&\#x202F; = \&\#x202F;6.34) (range from 5 to 35 points). In terms of gender, the men obtained an average score of 14.27 (SD\&\#x202F; = \& $\# \times 202 F ; 6.70$ ) and the women, an average score of 17.65 (SD\& \#x202F; = \&\#x202F;6.01).

In the dimension "not being able to access information", the participants' average score was 16.63 (SD\&\#x202F; =\&\#x202F;4.17) (range from 4 to 28 points). The average score for male participants was 16.12 (SD\&\#x202F; =\&\#x202F;4.00) while for female participants, it was 16.80 (SD\&\#x202F; = \&\#x202F;4.23).

The average score in the dimension "giving up convenience" was 19.98 (SD\&\#x202F; =\&\#x202F;5.50) (range from 5 to 35 points). Regarding gender, the men scored an average of 18 (SD\&\#x202F; = \& $\# \mathrm{x} 202 \mathrm{~F} ; 4.98)$. In the case of the women, the average score was 20.66 (SD\&\#x202F; = \&\#x202F;5.53).

In Portugal, two dimensions were determined; "not having access to information and connectivity" and "not being able to communicate". In the first dimension, the average score was 63.07 (SD\&\#x202F; = \& $\# \mathrm{x} 202 \mathrm{~F} ; 16.56$ ) (range from 14 to 98 points). Considering gender, the male participants scored an average of $51.75 \quad$ (SD\&\#x202F; = \& $\# \mathrm{x} 202 \mathrm{~F} ; 20.43)$ while the female participants scored an average of 64.69 (SD\&\#x202F; = \&\#x202F;15.37). In terms of the dimension "not being able to communicate", the average score was 30.75 (SD\& $\# \mathrm{x} 202 \mathrm{~F} ;=\& \# \mathrm{x} 202 \mathrm{~F} ; 6.89$ ) (range from 6 to 42 points). The average score for men was 27.44 (SD\&\#x202F; $=\& \# \times 202 F ; 7.91)$ while in the case of women, it was 31.22 (SD\&\#x202F; =\&\#x202F;6.64).

\subsection{Total nomophobia questionnaire score}

In Spain, the average questionnaire score was 78.84 (SD\&\#x202F; = $\& \# \mathrm{x} 202 \mathrm{~F} ; 18.91$ ) (range from 20 to 140 points). With regard to gender, the average score for men was 73.78 (SD\&\#x202F; = \&\#x202F;19.64), while women scored an average of 80.56 (SD\&\#x202F; = \& \#x202F;18.44).

With regard to Portugal, the average total score of the questionnaire was 93.82 (SD\&\#x202F; =\&\#x202F;21.98) (range from 20 to 140 points). Male participants scored an average of 79.19 (SD\&\#x202F; = \& \#x202F;25.39), while women obtained an average score of 95.91 (SD\& $\# \mathrm{x} 202 \mathrm{~F} ;=\& \# \mathrm{x} 202 \mathrm{~F} ; 20.75)$. In Table 2, the mean and standard deviation of each item corresponding to the Nomophobia questionnaire in Portugal can be found.

\subsection{Bivariate analysis}

In Spain, in relation to the first dimension, (1) not being able to communicate, no statistically significant differences were found between the genders for this dimension $(\mathrm{t}(128) \& \# \mathrm{x} 202 \mathrm{~F}$; $=\& \# \mathrm{x} 202 \mathrm{~F}$; 0.050; $\mathrm{p} \& \# \mathrm{x} 202 \mathrm{~F} ;=\& \# \mathrm{x} 202 \mathrm{~F} ; 0.960$ ). With regard to the second dimension, (2) losing connectedness, statistically significant differences were found in relation to gender $(\mathrm{t}(128) \& \# \mathrm{x} 202 \mathrm{~F} ;=\& \# \mathrm{x} 202 \mathrm{~F} ;-2.704 ; \mathrm{p}$ \&\#x202F; = \&\#x202F;0.008). Considering the third dimension, (3) not being able to access information, no statistically significant differences were found between genders $(\mathrm{t}(128) \& \# \mathrm{x} 202 \mathrm{~F} ;=\& \# \mathrm{x} 202 \mathrm{~F} ;-0.811 ; \mathrm{p} \&$ $\# \mathrm{x} 202 \mathrm{~F} ;=\& \# \mathrm{x} 202 \mathrm{~F} ; 0.419$ ). For the dimension (4) giving up convenience, statistically significant differences were found between genders $\quad(\mathrm{t}(128) \& \# \mathrm{x} 202 \mathrm{~F} ;=\& \# \mathrm{x} 202 \mathrm{~F} ;-2.424 ; \quad \mathrm{p} \& \# \mathrm{x} 202 \mathrm{~F} ;=$ \& $\# x 202 F ; 0.016)$. No correlation was found in any of the dimensions with regard to age, (rs\&\#x202F; =\&\#x202F;0.095; p\&\#x202F; = \& \#x202F;0.283), (rs: $0.080 ; \quad \mathrm{p} \& \# \mathrm{x} 202 \mathrm{~F} ;=\& \# \mathrm{x} 202 \mathrm{~F} ; 0.366), \quad$ (rs\& $\# \mathrm{x} 202 \mathrm{~F} ;=\& \# \mathrm{x} 202 \mathrm{~F} ; 0.001 ; \quad \mathrm{p} \& \# \mathrm{x} 202 \mathrm{~F} ;=\& \# \mathrm{x} 202 \mathrm{~F} ; 0.991), \quad$ (rs\& $\# \mathrm{x} 202 \mathrm{~F} ;=\& \# \mathrm{x} 202 \mathrm{~F} ; 0.084 ; \mathrm{p} \& \# \mathrm{x} 202 \mathrm{~F} ;=\& \# \mathrm{x} 202 \mathrm{~F} ; 0.340)$ respectively.

In Portugal, for the dimension "not having access to information and connectivity" significant differences were found in relation to sex $(\mathrm{t}$ (126)\&\#x202F; =\&\#x202F;-3.014; p\&\#x202F; = \&\#x202F;0.003). In relation to age, no correlation was found with this dimension (rs\& 
Table 2

Mean and standard deviation of each item corresponding to the Nomofobia questionnaire in Portugal.

\begin{tabular}{|c|c|c|c|c|c|c|c|c|c|c|c|c|c|c|c|c|}
\hline \multirow[t]{3}{*}{ Items } & \multicolumn{14}{|c|}{ Answers $^{\mathrm{a}}$} & \multirow[t]{3}{*}{$\bar{X}$} & \multirow[t]{3}{*}{ D.T. } \\
\hline & \multicolumn{2}{|l|}{1} & \multicolumn{2}{|l|}{2} & \multicolumn{2}{|l|}{3} & \multicolumn{2}{|l|}{4} & \multicolumn{2}{|l|}{5} & \multicolumn{2}{|l|}{6} & \multicolumn{2}{|l|}{7} & & \\
\hline & $\mathrm{n}$ & $\%$ & $\mathrm{n}$ & $\%$ & $\mathrm{n}$ & $\%$ & $\mathrm{n}$ & $\%$ & $\mathrm{n}$ & $\%$ & $\mathrm{n}$ & $\%$ & $\mathrm{n}$ & $\%$ & & \\
\hline Ítem 1 & 5 & 3.9 & 8 & 6.3 & 18 & 14.1 & 22 & 17.2 & 36 & 28.1 & 20 & 15.6 & 19 & 14.8 & 4.66 & 1.60 \\
\hline Ítem 2 & 2 & 1.6 & 4 & 3.1 & 14 & 10.9 & 14 & 10.9 & 51 & 39.8 & 20 & 15.6 & 23 & 18.0 & 5.03 & 1.40 \\
\hline Ítem 3 & 10 & 7.8 & 9 & 7.0 & 23 & 18.0 & 35 & 27.3 & 34 & 26.6 & 13 & 10.2 & 4 & 3.1 & 4.01 & 1.46 \\
\hline Ítem 4 & 2 & 1.6 & 4 & 3.1 & 11 & 8.6 & 14 & 10.9 & 45 & 35.2 & 23 & 18.0 & 29 & 22.7 & 5.20 & 1.43 \\
\hline Ítem 5 & 2 & 1.6 & - & - & 2 & 1.6 & 12 & 9.4 & 32 & 25.0 & 10 & 7.8 & 70 & 54.7 & 5.98 & 1.31 \\
\hline Ítem 6 & 8 & 6.3 & 1 & 8 & 11 & 8.6 & 16 & 12.5 & 45 & 35.2 & 14 & 10.9 & 33 & 25.8 & 5.05 & 1.64 \\
\hline Ítem 7 & 10 & 7.8 & 7 & 5.5 & 20 & 15.6 & 16 & 12.5 & 37 & 28.9 & 18 & 14.1 & 20 & 15.6 & 4.54 & 1.75 \\
\hline Ítem 8 & 18 & 14 & 9 & 7.0 & 32 & 25.0 & 24 & 18.8 & 27 & 21.1 & 11 & 8.6 & 7 & 5.5 & 3.73 & 1.67 \\
\hline Ítem 9 & 12 & 9.4 & 8 & 6.3 & 21 & 16.4 & 27 & 21.1 & 33 & 25.8 & 15 & 11.7 & 12 & 9.4 & 4.20 & 1.67 \\
\hline Ítem 10 & 1 & 0.8 & 4 & 3.1 & 19 & 14.8 & 17 & 13.3 & 44 & 34.4 & 19 & 14.8 & 24 & 18.8 & 4.97 & 1.43 \\
\hline Ítem 11 & - & - & 4 & 3.1 & 5 & 3.9 & 9 & 7.0 & 55 & 43.0 & 21 & 16.4 & 34 & 26.6 & 5.45 & 1.24 \\
\hline Ítem 12 & 1 & 0.8 & 4 & 3.1 & 6 & 4.7 & 23 & 18.0 & 45 & 35.2 & 21 & 16.4 & 28 & 21.9 & 5.20 & 1.33 \\
\hline Ítem 13 & 1 & 0.8 & 1 & 0.8 & 6 & 4.7 & 10 & 7.8 & 57 & 44.5 & 24 & 18.8 & 29 & 22.7 & 5.41 & 1.18 \\
\hline Ítem 14 & 4 & 3.1 & 1 & 0.8 & 18 & 14.1 & 22 & 17.2 & 48 & 37.5 & 16 & 12.5 & 19 & 14.8 & 4.82 & 1.41 \\
\hline Ítem 15 & 3 & 2.3 & 3 & 2.3 & 18 & 14.1 & 23 & 18.0 & 37 & 28.9 & 22 & 17.2 & 22 & 17.2 & 4.89 & 1.48 \\
\hline Ítem 16 & 10 & 7.8 & 5 & 3.9 & 23 & 18.0 & 37 & 28.9 & 29 & 22.7 & 13 & 10.2 & 11 & 8.6 & 4.20 & 1.55 \\
\hline Ítem 17 & 10 & 7.8 & 7 & 5.5 & 27 & 21.1 & 30 & 23.4 & 31 & 24.2 & 14 & 10.9 & 9 & 7.0 & 4.12 & 1.56 \\
\hline Ítem 18 & 10 & 7.8 & 5 & 3.9 & 29 & 22.7 & 31 & 24.2 & 36 & 28.1 & 14 & 10.9 & 3 & 2.3 & 4.03 & 1.42 \\
\hline Ítem 19 & 11 & 8.6 & 9 & 7.0 & 34 & 26.6 & 24 & 18.8 & 34 & 26.6 & 7 & 5.5 & 9 & 7.0 & 3.92 & 1.56 \\
\hline Ítem 20 & 12 & 9.4 & 8 & 6.3 & 22 & 17.2 & 27 & 21.1 & 19 & 14.8 & 14 & 10.9 & 26 & 20.3 & 4.40 & 1.88 \\
\hline
\end{tabular}

${ }^{\text {a }}$ Answers from 1 (Strongly disagree) to 7 (Strongly agree).

$\# x 202 F ;=\& \# x 202 F ;-0.114 ; \mathrm{p} \& \# x 202 F ;=\& \# x 202 F ; 0.199)$. For the following dimension, not being able to communicate, statistically significant differences were found regarding gender $(\mathrm{t}(126) \& \# \mathrm{x} 202 \mathrm{~F} ;=\&$ \#x202F;-2.081; p\&\#x202F; =\&\#x202F;0.039).

Comparing each item in terms of country of origin, statistically significant differences can be seen in relation to all items apart from in item 9 "If I cannot check my smartphone for a while, I feel a desire to check $i t$ " (Table 3). The average score for the whole sample was 86.27 (SD\& $\# \times 202 \mathrm{~F} ;=\& \# \times 202 \mathrm{~F} ; 21.78$ ), with statistically significant differences found when comparing total score and country of origin $(\mathrm{t}(256) \&$ $\# \times 202 F ;=\& \# x 202 F ;-5.867 ; \quad p \& \# \times 202 F ;=\& \# x 202 F ; 0.000)$. No significant differences were found in terms of gender $(\mathrm{t}(128) \& \# \mathrm{x} 202 \mathrm{~F} ;=$
\&\#x202F;1.794; p\&\#x202F; = \&\#x202F;0.075) or age (rs\&\#x202F; = \& $\# \mathrm{x} 202 \mathrm{~F} ; 0.084 ; \mathrm{p} \& \# \mathrm{x} 202 \mathrm{~F} ;=\& \# \mathrm{x} 202 \mathrm{~F} ; 0.339)$ regarding the total score in Spain. Lastly, in Portugal, significant differences were found between the sexes in terms of this factor $(\mathrm{t}(126) \& \# \mathrm{x} 202 \mathrm{~F} ;=\& \# \mathrm{x} 202 \mathrm{~F} ;-2.929 ; \mathrm{p} \&$ $\# \mathrm{x} 202 \mathrm{~F} ;=\& \# \mathrm{x} 202 \mathrm{~F} ; 0.004)$. However, no statistically significant differences were found in relation to age $(\mathrm{rs} \& \# \mathrm{x} 202 \mathrm{~F} ;=\&$ \#x202F; - 0.146; p\&\#x202F;=\&\#x202F;0.101).

\section{Discussion}

The aim of this study was to compare the levels of nomophobia experienced by nursing degree students from the University of Almeria

Table 3

Results of hypothesis contrast for each of the items with respect to the country.

\begin{tabular}{|c|c|c|}
\hline Item & $\mathrm{X}^{2}$ & $\mathrm{p}$ \\
\hline \multicolumn{3}{|l|}{ Factor III. Not being able to access information } \\
\hline 1 I would feel uncomfortable without constant access to information through my Smartphone. ${ }^{a}$ & 21.649 & 0.001 \\
\hline 2 I would be annoyed if I could not look information up on my smartphone when I wanted to do so ${ }^{\text {a }}$ & 14.086 & 0.029 \\
\hline 3 Being unable to get the news (e.g., happenings, weather, etc.) on my smartphone would make me nervous ${ }^{\mathrm{a}}$ & 18.256 & 0.006 \\
\hline 4 I would be annoyed if I could not use my smartphone and/or its capabilities when I wanted to do so ${ }^{\text {a }}$ & 20.147 & 0.003 \\
\hline \multicolumn{3}{|l|}{ Factor IV. Giving up convenience } \\
\hline 5 Running out of battery in my smartphone would scare me ${ }^{a}$ & 102.545 & 0.000 \\
\hline 6 If I were to run out of credits or hit my monthly data limit, I would panic ${ }^{\mathrm{a}}$ & 59.779 & 0.000 \\
\hline 7 If I did not have a data signal or could not connect to Wi-Fi, then I would constantly check to see if I had a signal or could find a Wi-Fi network ${ }^{\text {a }}$ & 16.789 & 0.010 \\
\hline 8 If I could not use my smartphone, I would be afraid of getting stranded somewhere & 35.568 & 0.000 \\
\hline 9 If I could not check my smartphone for a while, I would feel a desire to check it, If I did not have my smartphone with me, ${ }^{a}$ & 2.056 & 0.914 \\
\hline \multicolumn{3}{|l|}{ Factor I. Not being able to communicate } \\
\hline 10 I would feel anxious because I could not instantly communicate with my family and/or friends ${ }^{\mathrm{b}}$ & 38.920 & 0.000 \\
\hline 11 I would be worried because my family and/or friends could not reach me & 24.648 & 0.000 \\
\hline 12 I would feel nervous because I would not be able to receive text messages and calls ${ }^{\mathrm{b}}$ & 20.706 & 0.002 \\
\hline 13 I would be anxious because I could not keep in touch with my family and/or friends ${ }^{\mathrm{b}}$ & 44.388 & 0.000 \\
\hline 14 I would be nervous because I could not know if someone had tried to get a hold of me ${ }^{\mathrm{b}}$ & 21.736 & 0.001 \\
\hline 15 I would feel anxious because my constant connection to my family and friends would be broken ${ }^{\mathrm{b}}$ & 41.257 & 0.000 \\
\hline \multicolumn{3}{|l|}{ Factor II. Losing connectedness } \\
\hline 16 I would be nervous because I would be disconnected from my online identity ${ }^{\mathrm{a}}$ & 21.081 & 0.002 \\
\hline 17 I would be uncomfortable because I could not stay up-to-date with social media and online networks ${ }^{\mathrm{a}}$ & 18.827 & 0.004 \\
\hline 18 I would feel awkward because I could not check my notifications for updates from my connections and online networks ${ }^{\mathrm{a}}$ & 17.927 & 0.006 \\
\hline 19 I would feel anxious because I could not check my email messages ${ }^{\mathrm{a}}$ & 27.104 & 0.000 \\
\hline 20 I would feel weird because I would not know what to do ${ }^{a}$ & 15.170 & 0.019 \\
\hline
\end{tabular}

${ }^{\text {a }}$ Factor I - Not having access to information and connectivity. Portuguese version.

b Factor II - Not being able to communicate. Portuguese version. 
(Spain) and the Polytechnic Institute of Braganza (Portugal). The results highlight the high scores found among Portuguese participants, despite there being more studies regarding this topic in Spain.

Few research projects carried out in this context in relation to addictive behaviors towards mobile phones can be found, despite warnings regarding the dangerous relationship between these devices and young people (Souza, 2016). In Portugal, with the exception of three empirical studies on the subject of internet dependence (Gaspar and Carvalheira, 2012; Patrao et al., 2013; Pontes et al., 2016), there have been no scientific studies regarding the topic.

An increased use of smartphones for non-work related activities among healthcare professionals has been observed in clinical settings (Cho and Lee, 2016; McBride et al., 2015; Bautista and Lin, 2016). Furthermore, nurses admit to using their smartphones for personal communication while working (McBride et al., 2015). This increased use of smartphones could be related to nomophobia behaviors (Kaur and Sharma, 2015). Finally, as there is an instrument with established validity and reliability for nursing students, (Gutiérrez-Puertas et al., 2016), it would be interesting to explore the levels of nomophobia among this population.

With respect to being in a situation where you are not able to use your smartphone, statistically significant differences were found between the countries. In Spain, the highest scores were given to "totally agree" whereas in Portugal, the highest scores corresponded to "totally disagree" - the participants could remain calm without using their mobile phone. In contrast to these results, a study carried out by Smith (2015) found that $46 \%$ of participants responded that they "could not live without their mobile".

The Portuguese students felt more anxious than the Spanish students if their battery ran out. In the case of Spain, these figures are lower than those published by Dixit et al. (2010), who found that $54 \%$ of those surveyed felt anxious if they lost their phone or if it ran out of battery. In terms of the need to constantly look at one's mobile phone, no statistically significant differences were found between the countries, as the participants showed common behavioral patterns with regard to this factor.

The Portuguese students exhibited a greater necessity to communicate instantly with their family and friends, showing a need to contact them, especially when separated from them. Nevertheless, the results of a study carried out in Portugal by Francisco and Crespo (2012) indicated that excessive use of the internet via new technologies reduces family time, thus isolating the subjects.

However, both countries awarded high scores to worrying if their family and friends could not contact them, in terms of receiving both messages and calls, potentially leading to feelings of anxiety in both cases. Similarly, a study of Smartphone users revealed that the group which showed an addictive use of their mobiles experienced greater feelings of anxiety and depression to those who used them less frequently (Hwang et al., 2012).

The results highlighted the low scores that both countries gave to the importance of staying connected to social media. In Spain, the highest score was for the response "disagree" $(28.5 \%)$ while in Portugal, the most common response was "neither agree not disagree" (28.9\%). However, studies by Park and Cho (2015) have indicated that the most common activity among university nursing students is checking their social networks. Differences were found, however, with regard to staying up-to-date with social media, as a higher number of Portuguese students felt uncomfortable if they couldn't update it, whereas the majority of Spanish students indicated that they "neither agree nor disagree". These same differences between countries were found in relation to the item of not being able to see notifications and updates from contacts and social media. In other words, the Portuguese students showed a greater tendency to look at social networks and update information on said networks in comparison with Spanish nursing students. This could lead to problems regarding confidentiality and privacy if considered in the context of clinical practice (Cho and Lee,
2016). It has even been found that the use of social media is a significant predictor of mobile phone addiction (Salehan and Negahban, 2013).

Similar results were found in relation to emailing. The most common response from Portuguese students was "agree" when responding to feeling anxious when not able to check their email. Various studies have shown that this is one of the most used services by students, together with social networks (Kuss and Griffiths., 2017; Park and Cho, 2015).

Regarding the total score for the questionnaire, the Portuguese students obtained a higher score than the Spanish students. This also shows that both Spanish and Portuguese nursing students displayed higher than average nomophobia scores. These average scores could subsequently be identified with problems related to professional clinical practice, as indicated by Cho and Lee (2016). In line with these authors, and given the fact that these nursing students will be professionals in the future, an excessive and abusive use of smartphone during student years may indicate a higher threat towards patient safety when carrying out their nursing duties.

In relation to gender and the average questionnaire score, statistically significant differences were found; women displayed more nomophobic behaviors in the case of the Portuguese students. However, in Spain no statistically significant differences were found in relation to gender, although female participants scored slightly higher than the male participants. This contrasts with the results found in a study by Salehan and Negahban (2013), in which significant differences between the sexes were found. Previous studies have shown that women are more dependent on the services offered by the internet and are more likely to develop an addiction towards mobile telephones (Takao et al., 2009).

No statistically significant differences were found in terms of age and the total score in either country. However, in a study by Patrao et al. (2013), a relationship between internet dependence and age was found and in addition to this, Bianchi and Phillips (2005) also established that the problematic use of mobile phones is related, among other variables, to age. Younger people displayed higher levels of dependence. This difference between the two studies could be due to the small age range studied in our investigation, as all participants were aged between 17 and 38. In the Portuguese population, almost three quarters of under $25 \mathrm{~s}$ have been found to show signs of addiction to the digital world (Patrao et al., 2013).

The use of smartphones during class reduces students' academic performance (Mendoza et al., 2018). A study carried out with nursing students reported that the majority used their mobile phones in class, showing a moderate correlation between mobile phone use and the risk of developing nomophobia behaviors (Kaur and Sharma, 2015). Similarly, during practice the use of smartphones has been shown to distract nursing students (Cho and Lee, 2016). In this study, a high level of nomophobia was found among nursing students. Nursing professors should therefore educate this group of students on the negative impacts smartphone use can have on academic performance, together with how it can endanger patient safety and quality of care in a clinical setting. In addition to this, policies regulating smartphone use in academic and clinical environments should be established to ensure the appropriate use of mobile telephones in class and during practice.

\subsection{Limitations of the study}

When considering the results of this study, a set of limitations should be taken into account. Firstly, selection by convenience sampling does not allow for generalization of the results. Secondly, the results may be biased towards socially desirable responses. Authors such as Polit and Beck (2008) have found that students may hide their true responses, giving answers which reflect social values or professional expectations. Finally, the lack of research on the topic makes it difficult to carry out an adequate discussion of the findings, thus 
highlighting the novel and significant nature of this research, having been little studied in depth.

\section{Conclusions}

This study allows us to analyze the behavior of nursing students in relation to mobile phone use. The data collected in this study have led us to conclude that in the dimensions explored, considerable levels of nomophobia were present among the student populations analyzed, although the Portuguese population - especially women - displayed more severe nomophobia than the Spanish population. Considering the results obtained, it is important not only to improve training for nursing students but also to avoid risks derived from the misuse of mobile telephones in clinical practice, as use of such devices can lead to distractions and can put patient safety at risk. In addition, academic and health institutions should develop policies that regulate the use of mobile in educational and clinical context. In forming part of a student's education and training, nursing educators are well positioned to inform and guide regarding the importance of the appropriate use of new technologies in clinical settings. Further research is needed on the consequences of the misuse of new technologies on the patient and their care, together with how to further develop the role that nursing educators can play in encouraging appropriate smartphone use on placement.

\section{Funding}

This research received no specific grant from any funding agency in the public, commercial or not-for-profit sector.

\section{Conflicts of interest}

The authors declare no conflict of interest.

\section{Funding Sources}

Not applicable.

\section{Ethical approval details}

The research project was approved by the Department of Nursing, Physiotherapy and Medicine Research Committee at the University of Almeria. The ethics approval number is 08/2016.

\section{Acknowledgments} 451).

This work was supported by Health Science Research Group (CTS-

\section{References}

Aguilera-Manrique, G., Márquez-Hernández, V.V., Alcaraz-Córdoba, T., Granados-Gámez, G., Gutiérrez-Puertas, V.,Gutiérrez-Puertas, L., 2018. The relationship between nomophobia and the distraction associated with Smartphone use among nursing students in their clinical practicum. PloS One. 13(8), e0202953.

Alsos, O.A., Das, A., Svanaes, D., 2012. Mobile health IT: the effect of user interface and form factor on doctor-patient communication. Int. J. Med. Inf. 81 (1), 12-28.

Argumosa-Villar, L., Boada-Grau, J., Vigil-Colet, A., 2017. Exploratory investigation of theoretical predictors of nomophobia using the Mobile Phone Involvement Questionnaire (MPIQ). J. Adolesc. 56, 127-135.

Bae, S.M., 2017. The relationship between the type of smartphone use and smartphone dependence of Korean adolescents: National survey study. Child. Youth Serv. Rev. 81, 207-211.

Bautista, J.R., Lin, T.T., 2016. Sociotechnical analysis of nurses' use of personal mobile phones at work. Int. J. Med. Inf. 95 (1), 71-80.

Beyens, I., Frison, E., Eggermont, S., 2016. "I don't want to miss a thing": adolescents' fear of missing out and its relationship to adolescents' social needs, Facebook use, and Facebook related stress. Comput. Hum. Behav. 64, 1-8.

Bianchi, A., Phillips, J.G., 2005. Psychological predictors of problem mobile phone use. Cyberpsychol. Behav. 8 (1), 39-51.

Billieux, J., Philippot, P., Schmid, C., Maurage, P., De Mol, J., Van der Linden, M., 2014. Is dysfunctional use of the mobile phone a behavioural addiction? Confronting symptom-based versus process-based approaches. Clin. Psychol. Psychother. 22 (5), 460-468.

Cho, S., Lee, E., 2016. Distraction by smartphone use during clinical practice and opinions about smartphone restriction policies: a cross-sectional descriptive study of nursing students. Nurse Educ. Today 40, 128-133.

Dixit, S., Shukla, H., Bhagwat, A., Bindal, A., Goyal, A., Zaidi, A.K., Shrivastava, A., 2010. A study to evaluate mobile phone dependence among students of a medical college and associated hospital of central India. Indian J. Community Med. 35 (2), 339-341.

Francisco, R., Crespo, C., 2012. Adolescents "on the net and face": study of the relationship between the family environment and the use of the internet and social networks. In: Ortega, J. (Ed.), II Congresso Ibérico de Terapia Familiar. Lisboa, Portugal.

Gaspar, M.J., Carvalheira, A., 2012. Internet pornography consumption in a sample of Portuguese women. Psychol. Community Health 1 (2), 163-171.

González, M.A., Fernández, M.E.V., Urturi, A.F., Bregón, B.H., Moreno, M.F.M., Molinero, L.R., 2015. Use and risks of information and communication technologies in adolescents aged 13-18. Acta Pediatr. Esp. 73 (6), 146-151.

Gökçearslan, Ş., Mumcu, F.K., Haşlaman, T., Çevik, Y.D., 2016. Modelling smartphone addiction: the role of smartphone usage, self-regulation, general self-efficacy and cyberloafing in university students. Comput. Hum. Behav. 63, 639-649.

Gill, P.S., Kamath, A., Gill, T.S., 2012. Distraction: an assessment of smartphone usage in health care work settings. Risk Manag. Healthc. Pol. 5, 105-114.

Gutiérrez-Puertas, L., Márquez-Hernández, V.V., Aguilera-Manrique, G., 2016. Adaptation and validation of the Spanish version of the nomophobia questionnaire in nursing studies. Comput. Inform. Nurs. 34 (10), 470-475.

Habuchi, I., 2005. Accelerating reflexivity. In: Ito, M., Okabe, D., Matsuda, M. (Eds.), Personal, Portable, Pedestrian Mobile Phones in Japanese Life. Cambridge MIT Press, London, pp. 165-182.

Hwang, K.H., Yoo, Y.S., Cho, O.H., 2012. Smartphone over use and upper extremity pain, anxiety, depression, and interpersonal relationships among college students. J. Korea Contents Assoc. 12 (10), 365-375.

Kaur, A., Sharma, P., 2015. A descriptive study to assess the risk of developing nomophobia among students of selected nursing colleges Ludhiana, Punjab. Int. J. Psyc Nurs. 1 (2), 1-6.

Kuss, D.J., Griffiths, M.D., 2017. Social networking sites and addiction: ten lessons learned. Int. J. Environ. Res. Publ. Health 14 (3), 311-322.

Lee, S., Tam, C.L., Chie, Q.T., 2014. Mobile phone usage preferences: the contributing factors of personality, social anxiety and loneliness. Soc. Indicat. Res. 118 (3), 1205-1228.

McBride, D.L., LeVasseur, S.A., Li, D., 2015. Non-work-related use of personal mobile phones by hospital registered nurses. JMIR mHealth uHealth 3 (1), e3.

Mei, S., Chai, J., Wang, S.B., Ng, C.H., Ungvari, G.S., Xiang, Y.T., 2018. Mobile phone dependence, social support and impulsivity in Chinese university students. Int. J. Environ. Res. Publ. Health 15 (3), 504-510.

Mendoza, J.S., Pody, B.C., Lee, S., Kim, M., McDonough, I.M., 2018. The effect of cell phones on attention and learning: the influences of time, distraction, and nomophobia. Comput. Hum. Behav. 86, 52-60.

National Plan for the Reduction of Admissible Behaviors and Dependencies 2013-2020, 2013. Intervention service in additives behaviors and Dependencies. In: Intervention Service in Additive Behaviors and Dependencies Address, Lisboa, Portugal.

National Statistics Institute (Instituto Nacional de Estatística), 2014. More than Half of Internet Users Make it Mobile. Retrieved Jan, 2018, from. http://www.ine.es/ss/ Satellite $?$ L $=$ es_ES\&c $=$ INESeccion C\&cid $=1259925528782 \& \mathrm{p}=12547351106728$ pagename $=$ ProductosYServicios\%2FPYSLayout

Park, S.Y., Cho, S.H., 2015. Formation of social relationship through SNS and adolescents life satisfaction. J. Digit. Conver. 13 (2), 371-379.

Patrão, I., Rita, J., Pontes, H., 2013. Internet addiction and loneliness among Portuguese elementary school students: an exploratory quantitative study. Atención Primaria 45, 160-161.

Polit, D.F., Beck, C.T., 2008. Nursing Research: Generating and Assessing Evidence for Nursing Practice, second ed. Lippincott Williams \& Wilkins, Donnelley.

Pontes, H., Patrão, I., 2014. Estudo exploratório sobre as motivações percebidas no uso excessivo da internet em adolescentes e jovens adultos. Psychol. Community Health 3 (2), 90-102.

Pontes, H., Caplan, S., Griffiths, M., 2016. Psychometric validation of the generalized problematic internet use scale 2 in a Portuguese sample. Comput. Hum. Behav. 63, 823-833.

Salehan, M., Negahban, A., 2013. Social networking on smartphones: when mobile phones become addictive. Comput. Hum. Behav. 29, 2632-2639.

SecurEnvoy, 2012. 66\% of the Population Suffer from Nomophobia the Fear of Being without Retrieved Jan, 2018 from. https://www. securenvoy.com/blog/2012/02/16/ 66-of-the-population-suffer-from-nomophobia-thefear-of-being-without-theirphone/.

Sharma, N., Sharma, P., Sharma, N., Wavare, R.R., 2015. Rising concern of nomophobia amongst Indian medical students. Int. J. Res. Med. Sci. 3, 705-707.

Smith, A., 2015. US Smartphone Use in 2015. Pew research Center. Retrieved Jan, 2018 from. http://www.pewinternet.org/files/2015/03/PI_Smartphones_0401151.pdf.

Souza, L.A., 2016. Mobile and Teens: a Dangerous Relationship. Retrieved Jan, 2018 from. http://brasilescola.uol.com.br/curiosidades/celular-adolescentes-umarelacaoperigosa.html.

Takao, M., Takahashi, S., Kitamura, M., 2009. Addictive personality and problematic mobile phone use. The impact of the internet, multimedia and virtual reality on behavior and society. Cyberpsychol. Behav. 12 (5), 501-507.

Vanden Abeele, M.M., Antheunis, M.L., Schouten, A.P., 2016. The effect of mobile messaging during a conversation on impression formation and interaction quality. Comput. Hum. Behav. 62, 562-569.

Yildirim, C., Correia, A.P., 2015. Exploring the dimensions of nomophobia: development and validation of a self-reported questionnaire. Comput. Hum. Behav. 49, 130-137.

Yildirim, C., Sumuer, E., Adnan, M., Yildirim, S., 2016. A growing fear Prevalence of nomophobia among Turkish college students. Inf. Dev. 32 (5), 1322-1331. 